\title{
Antilymphocyte globulin for matched sibling donor transplantation in patients with myelofibrosis
}

\author{
Marie Robin, ${ }^{1}$ Sylvie Chevret, ${ }^{2}$ Linda Koster, ${ }^{3}$ Christine Wolschke, ${ }^{4}$ Ibrahim \\ Yakoub-Agha, ${ }^{5}$ Jean Henri Bourhis, ${ }^{6}$ Patrice Chevallier, ${ }^{7}$ Jan J. Cornelissen, ${ }^{8}$ \\ Péter Reményi, ${ }^{9}$ Johan Maertens, ${ }^{10}$ Xavier Poiré, ${ }^{11}$ Charles Craddock, ${ }^{12}$ Gérard \\ Socié, ${ }^{1}$ Maija Itälä-Remes, ${ }^{13}$ Harry C. Schouten, ${ }^{14}$ Tony Marchand, ${ }^{15}$ Jakob \\ Passweg, ${ }^{16}$ Didier Blaise, ${ }^{17}$ Gandhi Damaj, ${ }^{18}$ Zubeyde Nur Ozkurt, ${ }^{19}$ Tsila \\ Zuckerman, ${ }^{20}$ Thomas Cluzeau, ${ }^{21}$ Hélène Labussière-Wallet, ${ }^{22}$ Jörg \\ Cammenga, ${ }^{23}$ Donal McLornan, ${ }^{24}$ Yves Chalandon ${ }^{25}$ and Nicolaus Kröger ${ }^{3}$
}

Volume 104(6):1230-1236

${ }^{1}$ Hôpital Saint-Louis, APHP, INSERM 1131, Paris, France; ${ }^{2}$ Service de Biostatistique, Hôpital Saint-Louis, APHP, ESCTRA Team, INSERM UMR1153, Université Paris 7, France; ${ }^{3}$ EBMT Data Office Leiden, the Netherlands; ${ }^{4}$ University Hospital Eppendorf, Hamburg,

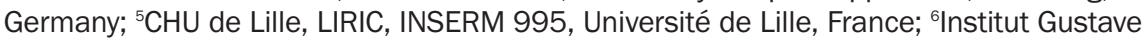
Roussy, INSERM U1186, Université Paris Saclay, Villejuif, France; ${ }^{7} \mathrm{CHU}$ Nantes, France; ${ }^{8}$ Department of Hematology, Erasmus University Medical Center, Rotterdam, the Netherlands; ' ${ }^{S}$ t. István \& St. Laszlo Hospital, Budapest, Hungary; ${ }^{10}$ University Hospital Gasthuisberg, Leuven, Belgium; ${ }^{11}$ Cliniques Universitaires St. Luc, Brussels, Belgium; ${ }^{12}$ Centre for Clinical Haematology, Queen Elizabeth Hospital, Birmingham, UK; ${ }^{13} \mathrm{HUCH}$ Comprehensive Cancer Center, Helsinki, Finland; ${ }^{14}$ University Hospital Maastricht, the Netherlands; ${ }^{15}$ Centre Hospitalier Universitaire de Rennes, France; ${ }^{16}$ University Hospital, Basel, Switzerland; ${ }^{17}$ Aix-Marseille University, Inserm, CNRS, Institut Paoli-Calmettes, CRCM, Marseille, France; ${ }^{18} \mathrm{CHU}$ Caen, France; ${ }^{19} \mathrm{Gazi}$ University Faculty of Medicine, Ankara, Turkey; ${ }^{20}$ Rambam Medical Center, Haifa, Israel; ${ }^{21}$ Université Cote d'Azur, CHU Nice, INSERM U1065, France; ${ }^{22}$ Centre Hospitalier Lyon Sud, France; ${ }^{23}$ University Hospital, Linköping, Sweden; ${ }^{24}$ Comprehensive Cancer Centre, Department of Haematology, King's College, London, UK and ${ }^{25} \mathrm{Hôpitaux}$ Universitaires de Genève and Faculty of Medicine, University of Geneva, Switzerland

\section{Correspondence: \\ MARIE ROBIN \\ marie.robin@aphp.fr \\ Received: July 11, 2018. \\ Accepted: January 9, 2019. \\ Pre-published: January 17, 2019.}

doi:10.3324/haematol.2018.201400

Check the online version for the most updated information on this article, online supplements, and information on authorship \& disclosures: www.haematologica.org/content/104/6/1230

\section{(C)2019 Ferrata Storti Foundation}

Material published in Haematologica is covered by copyright. All rights are reserved to the Ferrata Storti Foundation. Use of published material is allowed under the following terms and conditions:

https://creativecommons.org/licenses/by-nc/4.0/legalcode. Copies of published material are allowed for personal or internal use. Sharing published material for non-commercial purposes is subject to the following conditions:

https://creativecommons.org/licenses/by-nc/4.0/legalcode, sect. 3. Reproducing and sharing published material for commercial purposes is not allowed without permission in writing from the publisher.

\section{(c) (i) (s)}

\section{ABSTRACT}

T The use of antihuman T-lymphocyte immunoglobulin in the setting of transplantation from an HLA-matched related donor is still much debated. Acute and chronic graft-versus-host disease are the main causes of morbidity and mortality after allogeneic hematopoietic stem cell transplantation in patients with myelofibrosis. The aim of this study was to evaluate the effect of antihuman T-lymphocyte immunoglobulin in a large cohort of patients with myelofibrosis $(n=287)$. The cumulative incidences of grade II-IV acute graft-versus-host disease among patients who were or were not given antihuman T-lymphocyte immunoglobulin were $26 \%$ and $41 \%$, respectively. The corresponding incidences of chronic graft-versushost disease were $52 \%$ and $55 \%$, respectively. Non-adjusted overall survival, disease-free survival and non-relapse mortality rates were $55 \%$ versus $53 \%, 49 \%$ versus $45 \%$, and $32 \%$ versus $31 \%$, respectively, among the patients who were or were not given antihuman T-lymphocyte immunoglobulin. An adjusted model confirmed that the risk of acute graftversus-host disease was lower following antihuman T-lymphocyte immunoglobulin (hazard ratio, $0.54 ; P=0.010$ ) while it did not decrease the risk of chronic graft-versus-host disease. The hazard ratios for overall survival and non-relapse mortality were 0.66 and 0.64 , with $P$-values of 0.05 and 0.09 , respectively. Antihuman T-lymphocyte immunoglobulin did not influence disease-free survival, graft-versus-host disease, relapse-free survival or relapse risk. In conclusion, in the setting of matched related transplantation in myelofibrosis patients, this study demonstrates that antihuman T-lymphocyte immunoglobulin decreases the risk of acute graft-versushost disease without increasing the risk of relapse. 


\section{Introduction}

Primary myelofibrosis and myelofibrosis secondary to polycythemia vera or essential thrombocythemia are myeloproliferative neoplasms characterized by progressive fibrosis of the bone marrow and myeloid metaplasia in the spleen and liver. Disease severity can be assessed by a number of different prognostic scoring systems, which are able to predict survival without treatment in patients with primary and secondary myelofibrosis. ${ }^{1-5}$ The risk factors usually taken into account in these scores are disease-related symptoms, the degree of cytopenia or hyperleukocytosis, peripheral or bone marrow blast excess and age. Moreover, cytogenetics and somatic mutations provide additional prognostic power to these scoring instruments. ${ }^{3,6-9}$ According to the number of risk factors, the expected median survival from diagnosis can range from more than 10 years to less than 18 months. Allogeneic hematopoietic stem cell transplantation (HSCT) remains the only curative treatment in patients with myelofibrosis. One registry-based study demonstrated that patients with intermediate-2- or high-risk disease according to the Dynamic International Prognostic Scoring System (DIPSS) have an advantage in overall survival following transplantation and international expert consensus guidelines are in favor of transplantation in such patients. ${ }^{10,11}$ Cumulatively, overall survival after HSCT can range between $40 \%$ and $65 \%$ according to risk factors related to the disease, patient and type of donor. ${ }^{12-}$

${ }^{18}$ Results have been considered better with transplant from an HLA-matched sibling donor than an unrelated donor. However, acute and chronic graft-versus-host disease (GvHD) remain frequent causes of death in patients with myelofibrosis undergoing HSCT, often contributing to a relatively high transplant-related mortality of around $30 \% .{ }^{12-18}$ The optimal conditioning regimen and GvHD prophylaxis in these patients remain unknown. Two prospective studies of HSCT in myelofibrosis, in which the conditioning regimen and GvHD prophylaxis strategies were homogeneous, can be considered to compare GvHD rates and outcomes. In 2009, Kröger et al. reported on 103 myelofibrosis patients given conditioning with fludarabine, busulfan and the antihuman T-lymphocyte immune globulin Grafalon ${ }^{\circledast}$ at a dose of $30 \mathrm{mg} / \mathrm{kg}$ when the graft was from a matched related donor and $60 \mathrm{mg} / \mathrm{kg}$ when the donor was unrelated, combined with cyclosporine and a short course of methotrexate. With this regimen, including in vivo $\mathrm{T}$-cell depletion, the rate of acute grade II-IV GvHD was relatively low $(27 \%)$ and the incidence of chronic GvHD was $49 \%$. The relapse incidence was $32 \%$ in the setting of a matched related donor and $20 \%$ with an unrelated donor; these incidences were not statistically significantly different. Rondelli et al. subsequently reported a second prospective trial regarding HSCT in myelofibrosis using a fludarabine and melphalan platform in patients transplanted from a matched related donor, with the addition of Thymoglobulin ${ }^{\circledast}$ in patients with an unrelated donor. ${ }^{17}$ Acute GvHD rates were substantial, being $38 \%$ and $41 \%$ in the sibling donor group and unrelated donor group, respectively. Chronic GvHD rates did not differ significantly between the sibling donor (36\%) and unrelated donor (38\%) groups. Of particular note, mortality was dramatically higher $(68 \%)$ in the group of patients who underwent unrelated donor HSCT but the effect of antilymphocyte globulin (ATG) on this higher mortality risk remains undetermined. Collectively, from these two studies, it cannot be concluded unambiguously that ATG is beneficial in the setting of transplantation from a matched related donor. Recently, a randomized trial showed that ATG prevents chronic GvHD in patients with acute lymphoid leukemia or acute myeloid leukemia undergoing transplantation from an HLA-matched sibling donor following myeloablative conditioning regimens. ${ }^{19}$ Indeed, while acute GvHD was non-significantly lowered, the cumulative incidence of chronic GvHD dropped from 69\% without ATG to $32 \%$ with Grafalon ${ }^{\circledR}$ without increasing the risk of relapse. In this large European Society for Blood and Marrow Transplantation (EBMT) cohort, we aimed to determine the effect of ATG in the setting of HSCT for myelofibrosis using an HLA-matched sibling donor, which is of particular importance as data remain scarce given the rarity of the disease.

\section{Methods}

Consecutive patients transplanted from a matched sibling donor without ex vivo graft manipulation between 2007 and 2015 for myelofibrosis and registered in the EBMT registry were included in this study. Patients who received post-transplant treatment with cyclophosphamide or alemtuzumab as GvHD prophylaxis and those without sufficient information regarding blood cell counts prior to transplantation were excluded. A total of 287 patients were selected for the final analysis, among whom 135 received in vivo T-cell depletion while 152 did not.

The DIPSS was calculated according to the original definition. ${ }^{1}$ For some patients the data on peripheral blast count at the time of transplantation were missing; in these cases, the diagnostic blast count was used. General symptoms were either weight loss or sweating (only 2 patients had fever); data on constitutional symptoms were missing for 50 patients. Because information on the brand of drug used for T-cell depletion was not available in the registry, a stepwise hypothetical strategy was formulated to identify patients who received Thymoglobulin ${ }^{\circledast}$ and those who had received Grafalon ${ }^{\oplus}$ : ATG doses of $10 \mathrm{mg} / \mathrm{kg}$ or lower were considered as Thymoglobulin ${ }^{\oplus}$ whereas doses of $20 \mathrm{mg} / \mathrm{kg}$ or higher were considered as Grafalon ${ }^{\circledR}$ based on usual doses of each brand. This strategy was also checked by country in which the HSCT was performed, as some countries used only Grafalon ${ }^{\circledast}$, others used only Thymoglobulin ${ }^{\circledast}$ and some used both products.

Disease-free survival was defined as survival without disease relapse or progression documented in the registry. GvHD-free, relapse-free survival (GRFS) was defined as survival without disease relapse or progression, without grade III-IV acute GvHD and without chronic extensive GvHD documented in the registry.

Failure time data were analyzed used Kaplan-Meier estimates, log-rank tests and Cox modeling unless competing risks existed, when cumulative incidence curves, the Gray test and cause-specific Cox models were used. ${ }^{20}$ When estimating the cumulative incidence of chronic GvHD, patients were censored at the time of donor lymphocyte infusion, as previously reported. Based on frailty models, ${ }^{21}$ we tested whether there was a center effect on each outcome.

The study complied with regulatory requirements, the declaration of Helsinki and Good Practice standards. Independent review boards approved the study. Patients gave written informed consent. 


\section{Results}

\section{Patients and transplant characteristics}

The main patient, disease and transplant characteristics are described in Table 1. The median age of the participants was 56.9 years [interquartile range (IOR), 50.6-61.5 years], the minimum was 22.1 years and the maximum was 75.5 years. There was a majority of male patients $(68 \%)$. Patients who were not given ATG $(n=152)$ and those who were $(n=135)$ had similar characteristics regarding age, gender, and type of myelofibrosis (primary or secondary) but differed for other characteristics including splenectomy before transplant (38\% versus $9 \%$ ), DIPSS classification (intermediate- 2 or high: $59 \%$ versus $68 \%$ ), conditioning regimen (Table 1) and source of stem cells (bone marrow $17 \%$ versus $2 \%$ ). More patients in the ATG group received calcineurin inhibitors alone $(26 \%$ versus $7 \%$ ). Concerning pre-transplant therapy, five patients in the non-ATG cohort and 14 in the ATG cohort received the JAK inhibitor ruxolitinib (Novartis Pharmaceuticals, Geneva, Switzerland). Regarding the brand of ATG used in the ATG group, 37 patients received Grafalon ${ }^{\circledast}, 96$ received Thymoglobulin ${ }^{\oplus}$ and the brand was undetermined for two patients.

\section{Engraftment}

Six patients had primary graft rejection ( 3 in the ATG group and 3 in the non-ATG group). Four of these patients received a second HSCT and three of them were alive and in remission at the time of last reported follow-up. The cumulative incidences of neutrophil engraftment at day 60 were $96.3 \%$ [95\% confidence interval (95\% CI): 90.9\%$98.5 \%$ ] and $94.1 \%$ (95\% CI: $88.7 \%-96.9 \%)$ for the groups not given or given ATG, respectively $(P=0.35)$. The corresponding cumulative incidences of platelet recovery at 6 months were $68.4 \%$ (95\% CI: $60.3 \%-75.2 \%$ ) and $80.3 \%$ (95\% CI: $72.3 \%-86.1 \%)(P=0.09)$. Twenty-four patients (14 in the ATG group and 10 in the non-ATG group) had a secondary rejection at a median time of 9 months following HSCT and all but one had disease progression. Half of them received a second HSCT, which failed to achieve a remission.

\section{Outcomes}

The median time to onset of acute GvHD was 36 days. The cumulative incidence of grade II-IV acute GvHD was significantly higher in the group of patients who did receive ATG than in the group of patients who did not: $41.4 \%$ (95\% CI: $33.1 \%-49.5 \%$ ) versus $26.2 \%$ (95\% CI: $18.7 \%-34.3 \%)(P=0.0067)$ whereas the incidence of grade III-IV GvHD was similar in both groups (Figure 1). The median time to develop chronic GvHD was 198 days. The incidence of chronic GVHD was high $(>50 \%)$ in both groups of patients (Figure 1) without there being significant differences according to whether or not ATG was administered. Rates of chronic extensive GvHD were also similar in the two groups. The cumulative incidence of relapse was $24.4 \%$ (95\% CI: $16.5 \%-33.1 \%$ ) after ATG and $18.6 \%$ (95\% CI: $12.1 \%-26.1 \%)$ without ATG $(P=0.083)$. The rate of non-relapse mortality was $32.5 \%$ (95\% CI: $24.4 \%-40.7 \%$ ) with ATG versus $31 \%$ (95\% CI: $20.9 \%$ $41.6 \%$ ) without ATG. During the follow-up period, a total of 65 patients in the non-ATG group and 44 in the ATG group died. The primary cause of death was related to myelofibrosis progression in 34\% non-ATG patients and
Table 1. Patient, disease and transplant characteristics.

\begin{tabular}{lccc} 
& No ATG & ATG & P value \\
Total number & 152 & 135 & \\
Median age, years (IQR) & $56(50-61)$ & $58(51-62)$ & 0.07 \\
\hline Recipient gender & & & 0.53 \\
Male (\%) & $100(66)$ & $94(70)$ & \\
Female (\%) & $52(34)$ & $41(30)$ & \\
Median time from diagnosis & $41(15-120)$ & $30(9-84)$ & 0.13 \\
to transplant in months (IQR) & & & \\
\hline Disease & & & 0.07 \\
Primary myelofibrosis (\%) & $97(64)$ & $83(61)$ & \\
Secondary myelofibrosis (\%) & $44(29)$ & $50(37)$ & \\
Transformation into AML (\%) & $11(7)$ & $3(2)$ & \\
Date of transplantation & & & 0.02 \\
Before 2010 & $52(34)$ & $29(21)$ & \\
2010 and after & $100(66)$ & $106(79)$ & \\
\hline Splenectomy before transplant (\%) & $42(38)$ & $12(9)$ & $<0.0001$ \\
Lille score & & & 0.58 \\
Low & $30(20)$ & $31(23)$ & \\
Intermediate & $78(51)$ & $58(43)$ & \\
High & $44(29)$ & $46(34)$ & \\
\hline DIPSS score & & & \\
Low & $21(18)$ & $6(6)$ & \\
Intermediate-1 & $27(23)$ & $24(25)$ & \\
Intermediate-2 & $45(39)$ & $32(34)$ & \\
High & $23(20)$ & $32(34)$ & \\
Missing & 36 & 41 & \\
\hline
\end{tabular}

Missing

Conditioning regimen

TBI-cyclophosphamide or fludarabine

Busulfan-cyclophosphamide

Fludarabine-busulfan \pm other

Fludarabine-melphalan \pm other

FLAMSA

Fludarabine-thiotepa

GvHD prophylaxis

Calcineurin inhibitor alone

Calcineurin inhibitor and methotrexate

Calcineurin inhibitor and MMF

Other

Missing

Recipient CMV serostatus

Positive

Negative

Missing

Conditioning regimen

Reduced intensity

TBI-based

Source of stem cells

Marrow

Blood

Gender

Male recipient / female donor

Male recipient / male donor

Female recipient / female donor

Female recipient / male donor

Karnosfsky score, median [range]

$80 \%$ or more, $\mathrm{n}(\%)$

30 (20)

$18(12)$

37 (24)

$62(41)$

3 (2)

2 (1)

$8(5)$

$63(42)$

75 (49)

$4(3)$

$1(0.6)$

$2(1.5)$

$2(1.5)$

$110(81)$

$14(10)$

7 (5)

0

$39(29)$

$47(35)$

$46(34)$

$3(2)$

$\begin{array}{ll}95(63) & 82(61) \\ 57(37) & 52(39)\end{array}$

0

0

1

ATG: antilymphocyte globulin; IQR: interquartile range; AML: acute myeloid leukemia; DIPSS: Dynamic International Prognostic Scoring System; TBI: total body irradiation; FLAMSA: fludarabine, cytarabine and amascrine reduced intensity conditioning; GvHD: graft-versus-host disease; MMF: mycophenolate mofetil; CMV: cytomegalovirus. 
Acute grade II-IV GvHD

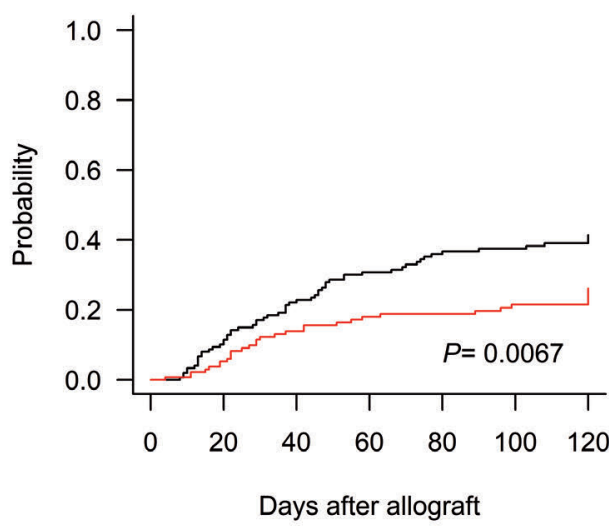

Chronic GvHD

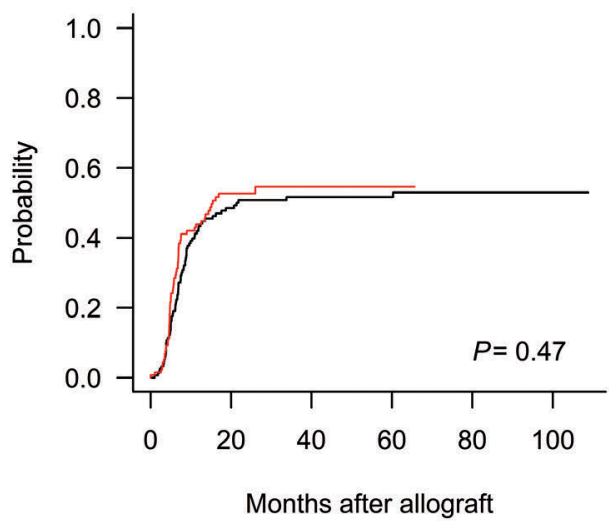

Acute grade III-IV GvHD

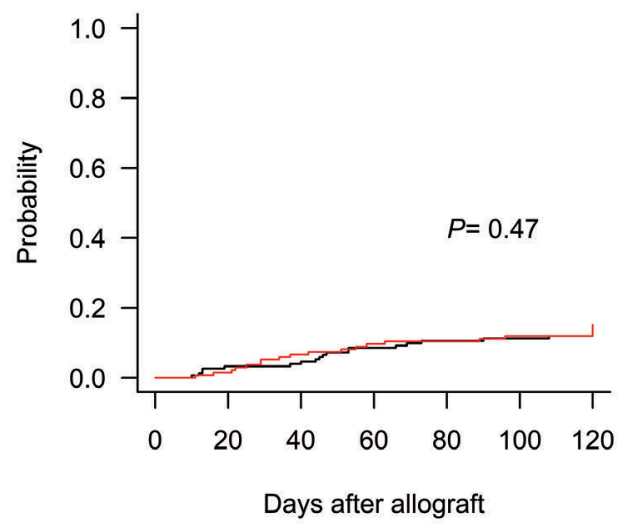

Chronic, extensive GvHD

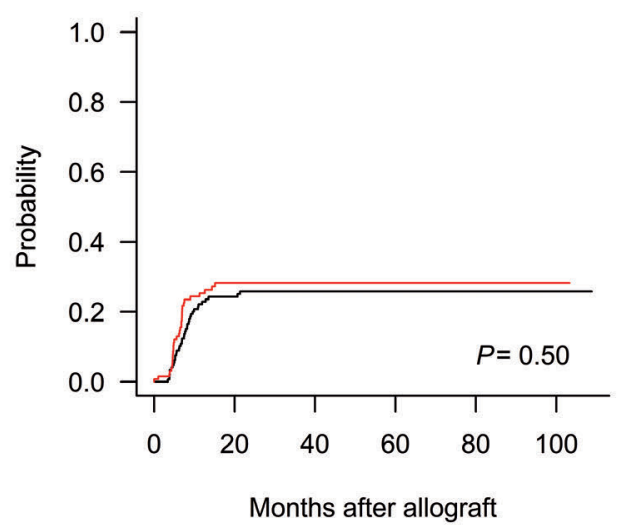

Figure 1. Acute and chronic graft-versus-host disease. The top panels show the incidences of grade II-IV and grade III-IV acute chronic graft-versus-host disease (GvHD). The bottom panels show the incidences of chronic GvHD and chronic extensive GvHD.

$29 \%$ in ATG patients. The 5-year overall survival (54.7\% versus $52.8 \%$ ), disease-free survival (49\% versus $44.7 \%$ ), and GRFS (29.3\% versus $23.6 \%$ ) rates were not significantly different between the two groups on univariate analysis (Table 2).

\section{Effects of antithymocyte globulin}

Due to disparities between the ATG and non-ATG groups, univariate analysis gave no clues on the effects of ATG. A multivariable model was generated to analyze the potential role of ATG on outcomes (Online Supplementary Table S1). Age was the strongest variable significantly associated with overall survival, disease-free survival and non-relapse mortality. Adjustments were made for age at transplantation, Lille score, Karnofsky Performance Status score, splenectomy before transplant, intensity of conditioning regimen (reduced intensity versus myeloablative) and source of stem cells (bone marrow versus peripheral blood). There was no effect of center on any outcome (Online Supplementary Table S2). Table 3 shows the effect of ATG for each outcome. The hazard ratio (HR) showed a benefit from ATG on overall survival (HR: 0.66, 95\% CI: $0.43-1.00 ; P=0.05$ ) and non-relpase mortality (HR: 0.64, 95\% CI: $0.39-1.07 ; P=0.09)$. The incidence of grade II-IV acute GvHD was significantly lower following the use of
ATG (HR: 0.54, 95\% CI: 0.34-0.86; $P=0.01$ ) but this was not the case for either grade III-IV acute GvHD or chronic extensive GvHD. In this model, ATG did not have a significant impact on disease-free survival, GRFS or relapse risk (see values in Table 3). Figure 2 shows the overall survival, disease-free survival and GRFS taking into account variables of the adjusted model.

\section{Discussion}

While there is some evidence that in vivo ATG can protect against the occurrence of acute and chronic GvHD, which may translate into a higher probability of GRFS in patients transplanted from an HLA matched related donor, ${ }^{19}$ there are no specific data from patients with myelofibrosis undergoing HSCT, because of the small numbers of such patients. In this retrospective study on behalf of the EBMT, we analyzed the impact of ATG in the largest documented cohort of patients with myelofibrosis transplanted with an HLA-matched related donor. Approximately half of the patients received ATG which is higher percentage than that previously reported by the Center for International Blood and Marrow Transplant Research (CIBMTR), according to which only $11 \%$ of 
patients with a matched related donor received ATG. ${ }^{22}$ ATG was used less frequently before 2010 (35\% versus $51 \%$ ). The majority of patients received a reduced intensity conditioning regimen and the preferred source of stem cells was peripheral blood. Our study demonstrated that acute GvHD was decreased following the use of ATG but there was no impact on chronic GvHD. The lack of attenuation of the risk of chronic GVHD is in contrast to the findings of the randomized trial comparing ATG versus no ATG in the setting of matched related donor HSCT published recently by Kröger et al. ${ }^{19}$ However, that study included patients with acute leukemia who were given myeloablative conditioning whereas our cohort received predominantly reduced intensity conditioning regimens and the study focused only on myelofibrosis. Of note, the rate of acute GvHD, even in patients who received ATG, was relatively high in our cohort $(26 \%)$ as compared to that in the prospective study cited above but not dissimilar to the rates in other studies including only patients with myelofibrosis. ${ }^{17,18}$ The rates of chronic GvHD were significantly high even after ATG; indeed, they were higher than previously reported in this disease setting. This raises the question of whether these myelofibrosis patients were more susceptible to developing chronic GvHD. We could postulate that these patients, who still had myelofibrosis slowly resolving in the first months after transplantation, had a pro-inflammatory profile able to trigger GvHD. Indeed, myelofibrosis is associated with elevated pro-inflammatory biomarkers such as those found in both autoimmune disease and immune dysregulation $^{23-26}$ and it has been demonstrated that the bone marrow remains fibrotic at 3 months following HSCT in approximately half of patients. ${ }^{27}$ Moreover, Hussain et al. reported that even in patients in whom fibrosis resolved following HSCT, the levels of pro-inflammatory cytokines and tissue remodeling factors could remain elevated. ${ }^{28}$ In contrast, other cytokines are downregulated following HSCT, such as the T-cell inhibitory receptor Tim-3 (T-cell
Table 2. Outcomes in patients with or without T-cell depletion (univariate).

\begin{tabular}{|c|c|c|c|}
\hline Outcomes: number of eve & nts $\begin{array}{c}\text { No ATG } \\
(n=152)\end{array}$ & $\underset{(n=135)}{\operatorname{ATG}}$ & $P$ value \\
\hline $\begin{array}{l}\text { leutrophil recovery } \\
\text { 0-day cum incidence }\end{array}$ & $\begin{array}{c}143 \\
94.1 \%(88.7-96.9)\end{array}$ & $\begin{array}{c}130 \\
96.3 \%(90.9-98.5)\end{array}$ & Gray: $P=0.35$ \\
\hline $\begin{array}{l}\text { Platelet recovery } \\
\text { 180-day cum incidence }\end{array}$ & $\begin{array}{c}104 \\
68.4 \%(60.3-75.2)\end{array}$ & $\begin{array}{c}108 \\
80.3 \%(72.3-86.1)\end{array}$ & Gray: $P=0.09$ \\
\hline $\begin{array}{l}\text { Grade II-IV acute GvHD } \\
\text { 4-month cum incidence }\end{array}$ & $\begin{array}{c}58 \\
41.4 \%(33.1-49.5)\end{array}$ & $\begin{array}{c}32 \\
26.2 \%(18.7-34.3)\end{array}$ & Gray: $P=0.0067$ \\
\hline $\begin{array}{l}\text { Grade III-IV acute GVHD } \\
\text { 4-month cum incidence }\end{array}$ & $\begin{array}{c}18 \\
11.9 \%(7.3-17.6)\end{array}$ & $\begin{array}{c}20 \\
15.1 \%(9.6-21.7)\end{array}$ & Gray $: P=0.47$ \\
\hline $\begin{array}{l}\text { Chronic GvHD* } \\
5 \text {-year cum incidence }\end{array}$ & $\begin{array}{c}75 \\
51.7 \%(43.1-59.6)\end{array}$ & $\begin{array}{c}62 \\
54.6 \%(44.5-63.7)\end{array}$ & Gray: $P=0.47$ \\
\hline $\begin{array}{l}\text { Extensive chronic GvHD * } \\
5 \text {-year cum incidence }\end{array}$ & $\begin{array}{c}37 \\
25.8 \%(18.9-33.3)\end{array}$ & $\begin{array}{c}33 \\
28.3 \%(20.4-36.7)\end{array}$ & Gray: $P=0.50$ \\
\hline $\begin{array}{l}\text { Relapse } \\
5 \text {-year cum incidence }\end{array}$ & $\begin{array}{c}24 \\
18.6 \%(12.1-26.1)\end{array}$ & $\begin{array}{c}29 \\
24.4 \%(16.5-33.1)\end{array}$ & Gray: $P=0.083$ \\
\hline $\begin{array}{l}\text { Non-relapse mortality } \\
5 \text {-year cum incidence }\end{array}$ & $\begin{array}{c}45 \\
32.5 \%(24.4-40.7)\end{array}$ & $\begin{array}{c}31 \\
31.0 \%(20.9-41.6)\end{array}$ & Gray: $P=0.56$ \\
\hline $\begin{array}{l}\text { Death } \\
\text { Median }(95 \% \text { CI }) \\
5 \text {-year OS }\end{array}$ & $\begin{array}{c}65 \\
3.4 \text { months (39.8-NA) } \\
54.7 \% \text { (45.1-63.1) }\end{array}$ & $\begin{array}{c}44 \\
64 \text { months (44.7-NA } \\
52.8 \%(42.1-66.3)\end{array}$ & $\begin{array}{l}\text { Logrank } P=0.43 \\
\text { A) }\end{array}$ \\
\hline
\end{tabular}

\begin{tabular}{lccc} 
Cause of death & & Fisher exact: \\
& & & $P=0.52$ \\
Relapse/progression & $22(34 \%)$ & $13(29 \%)$ & \\
Other & $35(54 \%)$ & $28(64 \%)$ & \\
Unknown & $8(12 \%)$ & $3(7 \%)$ & \\
\hline
\end{tabular}

Relapse or death Median $(95 \% \mathrm{CI})$

5 -year DFS

69 60 Log-rank: $P=0.46$

GvHD relapse death Median $(95 \% \mathrm{CI})$ 59.5 months (29-NA) 38.1 months (23.6-NA) $49.0 \%(40.6-59.0) \quad 44.7 \%(34.7-57.4)$

5 -year GRFS

95

$86 \quad$ Log-rank: $P=0.12$

9.9 months (8.2-17.7) 7.5 months (6.7-11.3) $29.3 \%(22.0-38.9) \quad 23.6 \%(15.8-35.2)$

*censored at donor lymphocyte infusion.ATG: antilymphocyte globulin; cum incidence: cumulative incidence; GvHD: graft-versus-host disease; OS: overall survival; DFS: disease-free survival; GRFS: GvHD-free, relapse-free survival.
OS

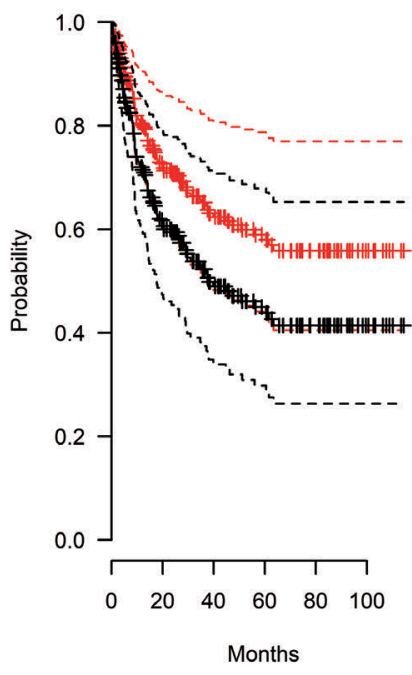

DFS

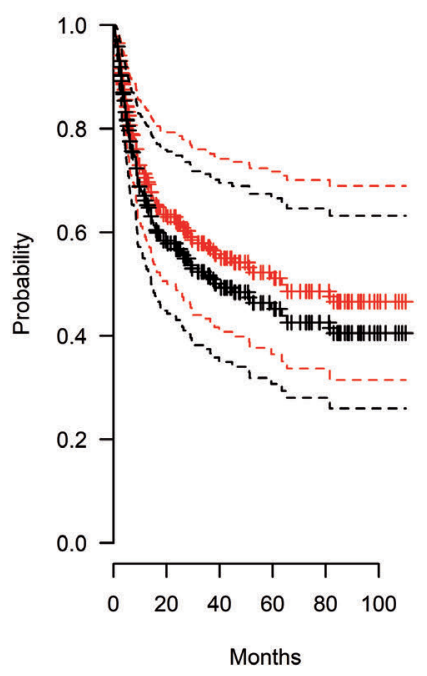

GRFS

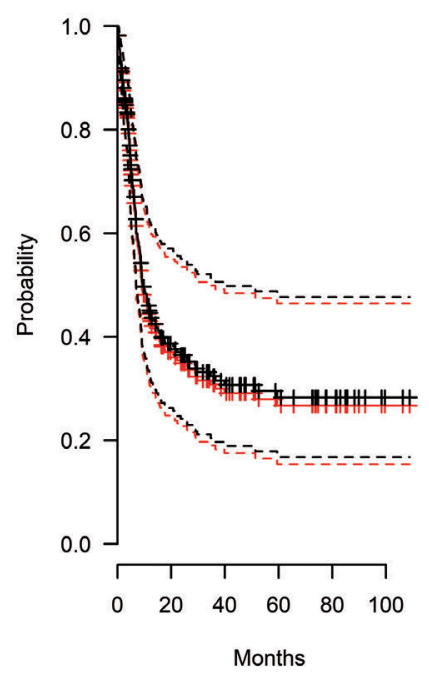

Figure 2. Adjusted survival curves. From left to right, overall survival (OS), disease-free survival (DFS), and graft-versus-host disease-free, relapse-free survival (GRFS) in patients who were given antilymphocyte globulin (red) and patients who were not given antilymphocyte globulin (black) with the 95\% confidence intervals (dotted lines). Curves have been adjusted according to multiple Cox models. 
immunoglobulin and mucin-domain containing-3), which may play a role in the control of GrHD. ${ }^{28,29}$

While ATG clearly decreased the risk of acute GvHD, the adjusted model showed a trend towards improved overall survival in patients who received ATG $(P=0.05)$. This higher risk of mortality without ATG may be explained by higher risk of acute GvHD even if the excess of mortality was not observed only in the first months post-transplant corresponding to GvHD. Treatment of GvHD and steroid-refractory GvHD may have contributed to mortality in patients who did not receive ATG. Of note, the definitions of acute and chronic GvHD in the registry were still restricted to the time of development of the disease, such that GvHD occurring in the 100 first days was considered as acute GvHD but we had no data regarding late acute $\mathrm{GvHD}$ which is considered as chronic GvHD in this study. Indeed, the classification of acute and chronic GvHD was not made according to the latest National Institutes of Health (NIH) consensus and chronic GvHD may have been overestimated because of the inclusion of cases of late acute GvHD. ${ }^{30}$ Our analysis was based on registry data and GvHD was not recoded a posteriori according to the NIH classification. GRFS, which captures both severe acute and severe chronic GvHD, is an important endpoint in this setting and showed no difference according to the use or not of ATG. Of note, even if the risk of chronic GvHD is mostly influenced by previous acute $\mathrm{GvHD}$, other variables, such as the management of immunosuppressive therapy and cellular therapy may influence the risk of chronic GvHD. Finally, this is the first study that shows a trend to lower mortality in patients receiving ATG. Four prospective trials conducted in the setting of transplantation from unrelated donors and the aforementioned study in the matched sibling donor setting did not find a significant overall survival advantage in patients given ATG..$^{19,31-33}$ In contrast, one large prospective randomized trial found that overall survival was lower in patients receiving ATG in the setting of unrelated donor transplantation (whether given reduced intensity or myeloablative conditioning). ${ }^{34}$ It must be considered however that the dose of ATG and the manufacturing process of these products may also have an impact on outcomes and differ in the various prospective trials. In the present
Table 3. Adjusted effect of antilymphocyte globulin on outcomes; adjustment for age at transplant, Lille score, Karnofsky Performance Status, splenectomy, conditioning regimen intensity and source of stem cells.

\begin{tabular}{lcc} 
& $\begin{array}{c}\text { Hazard ratio (96\% CI) } \\
\text { AIG versus none }\end{array}$ & P value \\
\hline Overall survival & $0.66(0.43-1.00)$ & 0.05 \\
Relapse & $1.31(0.71-2.42)$ & 0.39 \\
\hline Non-relapse mortality & $0.64(0.39-1.07)$ & 0.09 \\
Grade II-IV acute GvHD & $0.54(0.34-0.86)$ & 0.01 \\
\hline Grade III-IV acute GvHD & $1.11(0.54-2.28)$ & 0.77 \\
Chronic extensive GvHD & $1.17(0.72-1.91)$ & 0.52 \\
\hline Disease-free survival & $0.86(0.59-1.27)$ & 0.46 \\
GRFS & $1.05(0.76-1.46)$ & 0.74 \\
\hline
\end{tabular}

ATG: antilymphocyte globulin; GvHD: graft-versus-host disease; GRFS: GvHD-free, relapse-free survival.

EBMT study, we were able to identify patients who received Thymoglobulin ${ }^{\circledast}$ or Grafalon ${ }^{\oplus}$ but due to small numbers in the subgroups, we could not draw conclusions regarding the specific impact of the individual products on outcomes. Absolute lymphocyte count may also contribute to the efficiency of ATG and this factor could not be studied here from the registry data. ${ }^{34}$ We can only postulate that myelofibrosis patients, who usually have not received intensive chemotherapy, may arrive at transplantation with subnormal lymphocyte counts, which can be targeted by ATG. With regards to relapse risk, it was not confirmed in the multivariable model that ATG increased the risk of relapse; however, relapse continued to occur late after HSCT without a real plateau occurring, highlighting the importance of long-term monitoring in myelofibrosis patients who undergo HSCT.

In conclusion, this retrospective data analysis of myelofibrosis patients undergoing HSCT whose data were included in the EBMT registry confirms that in vivo ATG is able to protect against acute GvHD and possibly may decrease mortality rates. A prospective study is needed to confirm the role of ATG in myelofibrosis patients transplanted from an HLA-matched related donor.

\section{References}

1. Passamonti F, Cervantes F, Vannucchi AM, et al. Dynamic International Prognostic Scoring System (DIPSS) predicts progression to acute myeloid leukemia in primary myelofibrosis. Blood. 2010;116(15):28572858.

2. Cervantes F, Dupriez B, Pereira A, et al. New prognostic scoring system for primary myelofibrosis based on a study of the International Working Group for Myelofibrosis Research and Treatment. Blood. 2009;113(13):2895-2901.

3. Gangat N, Caramazza D, Vaidya R, et al. DIPSS Plus: a refined Dynamic International Prognostic Scoring System for primary myelofibrosis that incorporates prognostic information from karyotype, platelet count, and transfusion status. J Clin Oncol. 2011;29(4):392-397.
4. Dupriez B, Morel P, Demory JL, et al. Prognostic factors in agnogenic myeloid metaplasia: a report on 195 cases with a new scoring system. Blood. 1996;88(3):10131018.

5. Cervantes F, Barosi G, Demory JL, et al. Myelofibrosis with myeloid metaplasia in young individuals: disease characteristics, prognostic factors and identification of risk groups. Br J Haematol. 1998;102(3):684-690.

6. Guglielmelli P, Lasho TL, Rotunno G, et al The number of prognostically detrimental mutations and prognosis in primary myelofibrosis: an international study of 797 patients. Leukemia. 2014;28(9):1804-1810.

7. Guglielmelli P, Lasho TL, Rotunno G, et al. MIPSS70: mutation-enhanced international prognostic score system for transplantationage patients with primary myelofibrosis. J Clin Oncol. 2018;36(4):310-318.

8. Tefferi A, Lasho TL, Finke CM, et al. CALR vs JAK2 vs MPL-mutated or triple-negative myelofibrosis: clinical, cytogenetic and molecular comparisons. Leukemia. 2014;28(7):1472-1477

9. Vannucchi AM, Lasho TL, Guglielmelli P, et al. Mutations and prognosis in primary myelofibrosis. Leukemia. 2013;27(9):18611869.

10. Kröger N, Giorgino T, Scott BL, et al. Impact of allogeneic stem cell transplantation on survival of patients less than 65 years of age with primary myelofibrosis. Blood. 2015;125(21):3347-3350.

11. Kröger NM, Deeg JH, Olavarria E, et al. Indication and management of allogeneic stem cell transplantation in primary myelofibrosis: a consensus process by an EBMT/ELN international working group. Leukemia. 2015;29(11):2126-2133.

12. Guardiola P, Anderson JE, Bandini G, et al Allogeneic stem cell transplantation for 
agnogenic myeloid metaplasia: a European Group for Blood and Marrow Transplantation, Société Française de Greffe de Moelle, Gruppo Italiano per il Trapianto del Midollo Osseo, and Fred Hutchinson Cancer Research Center Collaborative Study. Blood. 1999;93(9):2831-2838.

13. Deeg HJ, Gooley TA, Flowers MED, et al. Allogeneic hematopoietic stem cell transplantation for myelofibrosis. Blood. 2003;102(12):3912-3918.

14. Kerbauy DMB, Gooley TA, Sale GE, et al. Hematopoietic cell transplantation as curative therapy for idiopathic myelofibrosis, advanced polycythemia vera, and essential thrombocythemia. Biol Blood Marrow Transplant. 2007;13(3):355-365.

15. Patriarca F, Bacigalupo A, Sperotto A, et al. Allogeneic hematopoietic stem cell transplantation in myelofibrosis: the 20-year experience of the Gruppo Italiano Trapianto di Midollo Osseo (GITMO). Haematologica. 2008;93(10):1514-1522.

16. Robin M, Tabrizi R, Mohty M, et al. Allogeneic haematopoietic stem cell transplantation for myelofibrosis: a report of the Société Française de Greffe de Moelle et de Thérapie Cellulaire (SFGM-TC). Br J Haematol. 2011;152(3):331-339.

17. Rondelli D, Goldberg JD, Isola L, et al. MPDRC 101 prospective study of reduced-intensity allogeneic hematopoietic stem cell transplantation in patients with myelofibrosis. Blood. 2014;124(7):1183-1191.

18. Kröger N, Holler E, Kobbe G, et al. Allogeneic stem cell transplantation after reduced-intensity conditioning in patients with myelofibrosis: a prospective, multicenter study of the Chronic Leukemia Working Party of the European Group for Blood and Marrow Transplantation. Blood. 2009;114 (26):5264-5270.

19. Kröger N, Solano C, Wolschke C, et al. Antilymphocyte globulin for prevention of chronic graft-versus-host disease. $\mathrm{N}$ Engl J
Med. 2016;374(1):43-53

20. Gooley TA, Leisenring W, Crowley J, Storer $\mathrm{BE}$. Estimation of failure probabilities in the presence of competing risks: new representations of old estimators. Stat Med. 1999;18(6):695-706.

21. Vaupel JW, Manton KG, Stallard E. The impact of heterogeneity in individual frailty on the dynamics of mortality. Demography. 1979;16(3):439-454.

22. Ballen KK, Shrestha S, Sobocinski KA, et al. Outcome of transplantation for myelofibrosis. Biol Blood Marrow Transplant. 2010;16(3):358-367.

23. Kristinsson SY, Björkholm M, Hultcrantz M, Derolf AR, Landgren O, Goldin LR. Chronic immune stimulation might act as a trigger for the development of acute myeloid leukemia or myelodysplastic syndromes. Clin Oncol. 2011;29(21):2897-2903.

24. Kristinsson SY, Landgren O, Samuelsson J, Björkholm M, Goldin LR. Autoimmunity and the risk of myeloproliferative neoplasms. Haematologica. 2010;95(7):12161220.

25. Hasselbalch HC. Perspectives on chronic inflammation in essential thrombocythemia, polycythemia vera, and myelofibrosis: is chronic inflammation a trigger and driver of clonal evolution and development of accelerated atherosclerosis and second cancer? Blood. 2012;119(14):3219-3225.

26. Hasselbalch HC, Bjørn ME. MPNs as inflammatory diseases: the evidence, consequences, and perspectives. Mediators Inflamm. 2015;2015:102476.

27. Kröger N, Zabelina $\mathrm{T}$, Alchalby $\mathrm{H}$, et al Dynamic of bone marrow fibrosis regression predicts survival after allogeneic stem cell transplantation for myelofibrosis. Biol Blood Marrow Transplant. 2014;20(6):812815.

28. Hussein K, Stucki-Koch A, Alchalby H, Triviai I, Kröger N, Kreipe H. Cytokine expression pattern in bone marrow microenvironment after allogeneic stem cell transplantation in primary myelofibrosis Biol Blood Marrow Transplant. 2016;22(4): 644-650.

29. Anderson AC. Tim-3: an emerging target in the cancer immunotherapy landscape. Cancer Immunol Res. 2014;2(5):393-398.

30. Filipovich $\mathrm{AH}$, Weisdorf $\mathrm{D}$, Pavletic $\mathrm{S}$, et al National Institutes of Health consensus development project on criteria for clinical trials in chronic graft-versus-host disease: I Diagnosis and staging working group report. Biol Blood Marrow Transplant. 2005;11(12):945-956.

31. Bacigalupo A, Lamparelli T, Bruzzi P, et al Antithymocyte globulin for graft-versushost disease prophylaxis in transplants from unrelated donors: 2 randomized studies from Gruppo Italiano Trapianti Midollo Osseo (GITMO). Blood. 2001;98(10):29422947.

32. Finke J, Bethge WA, Schmoor C, et al Standard graft-versus-host disease prophylaxis with or without anti-T-cell globulin in haematopoietic cell transplantation from matched unrelated donors: a randomised, open-label, multicentre phase 3 trial. Lancet Oncol. 2009:10(9):855-864.

33. Walker I, Panzarella T, Couban S, et al. Pretreatment with anti-thymocyte globulin versus no anti-thymocyte globulin in patients with haematological malignancies undergoing haemopoietic cell transplantation from unrelated donors: a randomised, controlled, open-label, phase 3, multicentre trial. Lancet Oncol. 2016;17(2):164-173.

34. Soiffer RJ, Kim HT, McGuirk J, et al. Prospective, randomized, double-blind, phase III clinical trial of anti-T-lymphocyte globulin to assess impact on chronic graftversus-host disease-free survival in patients undergoing HLA-matched unrelated myeloablative hematopoietic cell transplantation. J Clin Oncol. 2017;35(36): 40034011 